\title{
Presentation accuracy of Web animation methods
}

\author{
WILLIAM C. SCHMIDT \\ State University of New York, Buffalo, New York
}

\begin{abstract}
Several Web animation methods were independently assessed on fast and slow systems running two popular Web browsers under MacOS and Windows. The methods assessed included those requiring programming (Authorware, Java, Javascript/Jscript), browser extensions (Flash and Authorware), or neither (animated GIF). The number of raster scans that an image in an animation was presented for was counted. This was used as an estimate of the minimum presentation time for the image when the software was set to update the animation as quickly as possible. In a second condition, the image was set to be displayed for $100 \mathrm{msec}$, and differences between observed and expected presentations were used to assess accuracy. In general, all the methods except Java deteriorated as a function of the speed of the computer system, with the poorest temporal resolutions and greatest variability occurring on slower systems. For some animation methods, poor performance was dependent on browser, operating system, system speed, or combinations of these.
\end{abstract}

As the Internet has become more commonplace in contemporary society, there has been an associated increase in the interest of psychologists in using the World-Wide Web for data collection. As the graphics capabilities of Web browsers (e.g., Netscape Navigator, Microsoft Internet Explorer, Opera Software, etc.) and associated network-based display presentation methods increase, the opportunity for psychologists to carry out precisely timed, graphics-intensive experiments on the World-Wide Web becomes more attractive. Reports of experiments using the Java programming language (Francis, Neath, \& Surprenant, 2000; Hecht, Oesker, Kaiser, Civelek, \& Stecker, 1999; Stevenson, Francis, \& Kim, 1999), client-side Javascript programs (Baron \& Siepman, 2000; Horswill \& Coster, 2001), Macromedia Authorware programs (McGraw, Tew, \& Williams, 2000a, 2000b; Williams, McGraw, \& Tew, 1999), and server-based experiment delivery (Krantz, Ballard, \& Scher, 1997) have made graphical experiments on the World-Wide Web a reality.

At the same time that mainstream experimenters are interested in tapping the Web medium for experiment delivery, critical questions about the control of stimulus delivery and the collection of response time data remain unanswered. Can the methods reported be trusted to elicit representative data of even restricted population subgroups, given the wide diversity of hardware (e.g., Intelcompatible vs. PowerPC-based systems with heterogeneous clock speeds, screen refresh rates, monitors, etc.), operating systems (e.g., various versions of Windows, MacOS, Linux, Solaris, etc.), Web browsers, client-side

Thanks to Sam Folby and Tom Fritz for building the photo detector hardware. Correspondence concerning this article should be addressed to W. C. Schmidt, Department of Psychology, State University of New York, 355 Park Hall, Buffalo, NY 14260 (e-mail: wcswcs@acsu. buffalo.edu). languages (i.e., Java, Javascript, and JScript), versions of browser (e.g., Netscape 1.0, 2.0, 3.0, 4.x, etc.), language interpreter manufacturers (e.g., Symantec Java, Microsoft Java, Netscape Javascript, Microsoft JScript, etc.), plug-ins (e.g., Flash, Shockwave, Authorware Web Player, etc.), and combinations of these that potential subjects are using (e.g., Microsoft Internet Explorer 4.5 for MacOS with Apple's Macintosh Runtime for Java 2.2, or Netscape Navigator for Windows98 with Microsoft Java 1.2 , etc.)?

Similarly, if data differ between Web-based versus laboratory-based collection methods, is the source possibly due to the technology involved? Could subjects be unrepresentative in some experiments, not only because they are self-selected volunteers, but also because, once arriving at the experiment Web site, they were allowed to participate only because they had an adequate browser configuration (or the computer skills, motivation, and patience to upgrade) to participate in an experiment? What is the level of accuracy for various response time collection methods? Are inaccuracies introduced by different stimulus delivery methods?

The present work addresses only the last of the above questions: What degree of accuracy exists in common stimulus delivery methods that are available for use in Web experiments? And if there are inaccuracies, to what degree do they exist, and can any compensatory measures be taken to minimize increased variability? Note that this problem is part of what is generally referred to when researchers consider timing accuracy. If response time data collection is the goal, the researcher wishes to synchronize the stimulus presentation with the clock being used to record durations. One problem is verifying that the system accurately began stimulus delivery at a given time, and a second problem is verifying that stopping the clock was accurately triggered by the subject's response. The present paper is concerned with only the first of these 
issues - presentation accuracy, regardless of whether the dependent measure is response time or report-based measures. Presentation accuracy (McKinney, MacCormac, $\&$ Welsh-Bohmer, 1999) and response detection accuracy (Myors, 1999) have recently been examined for Windowsbased computer systems, and reports exist on response detection accuracy for a variety of different computer platforms (e.g., Eichstaedt, 2001, for Java; Finney, 2001, for Linux; Graves \& Bradley, 1991, for DOS).

\section{Auditory Versus Visual Stimuli}

Auditory stimulus delivery is highly accurate, owing to the inherently temporal nature of the stimulus. Internet experiments often rely on the playing of specialized files (e.g., .wav, .au) that encode the temporal frequency of the stimulus as a part of their basic structure and store the raw digital data that is to be turned into sound. These files are played back in accurate manner by necessary components of the operating system that generally handle sound presentation on specialized hardware and are likely to be as precise as the operating system and hardware permit (Welch \& Krantz, 1996). In contrast, methods that rely on third-party players that interpret and implement the encoded sounds (e.g., MIDI) may not be as accurate, since the playback algorithms may introduce timing inaccuracies or may vary on the basis of processor speed. Nonetheless, researchers at least know that they can trust the accuracy of sound formats that store the raw digital information and can minimize variability in presentation by using such formats. For this reason the accuracy of auditory stimulus delivery will not be examined further.

In contrast to auditory stimuli, graphical stimuli are inherently spatial. Any changes introduced in the stimulus over time to produce animation require unique approaches implemented at the level of the software presenting the stimulus. As was mentioned, researchers have used Java (Francis et al., 2000; Hecht et al., 1999; Stevenson et al., 1999), Javascript/JScript (Horswill \& Coster, 2001), and Authorware (McGraw et al., 2000a, 2000b) programs for visual stimulus delivery. Another popular candidate method is dynamic hypertext markup language (DHTML), which involves browser-implemented rendering methods that are activated and controlled by Javascript/Jscript programs. Additional Web animation possibilities are provided by Flash movies and animated graphic interchange format (GIF) images. Because the delivery of such stimuli are somewhat dependent on the particular underlying software layers (i.e., browser manufacturer and version, as well as Java or Javascript/JScript interpreters and the operating system), there is a need to evaluate the precision of such methods. In addition to varying levels of software, the hardware used presents additional variability (see Krantz, 2000).

How temporally accurate is the presentation of graphical material on the Web? This is of importance to any researcher wishing to control the durations or intervals of a series of images presented to their subjects. On laboratory computers, the hardware and software settings can be controlled. For instance, given the vertical refresh rate of the monitor (the frequency of updating by the electron gun that fires electrodes at the cathode ray tube), an experimenter knows that stimulus durations can roughly be multiples of whole-screen presentations, or frames. As Krantz (2000) demonstrated, even then there is variability owing to hardware (i.e., phosphor persistence). For Web presentation, however, this problem is compounded because neither the software implementing the experiment nor the hardware (or its settings) that the experiment is run on can be precisely controlled or held constant.

An array of software animation methods suitable for delivering stimuli on networked systems is surveyed below. Methods include those requiring programming (Java, Javascript/JScript, and Authorware) or browser extensions (Flash and Authorware), as well as those that do not (animated GIF). How to produce animations by using each method is briefly discussed, and the level of presentation accuracy obtainable is determined on the basis of an assessment that uses fast, up-to-date client computer systems and slower systems in order to get an idea of the range of performance that can be expected in a heterogeneous environment. Each system was first assessed in terms of the fastest animation performance that it could produce, in an effort to estimate the minimal durations achievable by the method. In addition, each system was assessed when a particular timing interval was specified. In this case, the error between the timing stipulated in the stimulus generation and that actually obtained across several browser versions, operating system platforms, and speeds of computer systems was used to estimate presentation timing accuracy. The conclusions summarize the findings by contrasting the accuracy of different animation methods.

\section{GENERAL METHOD}

The general approach to examining presentation accuracy relied on determining the fastest possible screen updating achieved for each of several popular visual presentation methods. In addition, for a particular specified duration, the difference between the stipulated presentation timing (e.g., programmed or specified on the basis of the particular method) and the actual timing obtained was assessed.

Obtained timing in all conditions was measured using a photo detector system pointed at the client computer's monitor. The photo detector system signaled abrupt changes in input with under a 100- $\mu$ sec level of accuracy (McKinney et al., 1999). The photo detector system's signal was input to a Macintosh 3400c powerbook's audio input, where the waveform was digitized and the delivered timing assessed using Soundedit16 (Macromedia). The input was sampled at a rate high enough $(44 \mathrm{kHz})$ that the measurements made were accurate to under $1 \mathrm{msec}$. When a white stimulus was presented on the computer monitor, the photo detectors signaled each pass of the raster gun - a component of cathode ray tube displays that paints the phosphor screen with a stream of electrons 
starting from the top left corner and proceeding rightward and to the bottom in sequential lines. When a black image was presented, no signal was registered by the photo detectors. Hence, by oscillating white versus black stimuli in a square wave, it was possible to determine the timing achieved for an average cycle.

For each of the animation methods examined, a black to white screen transition was presented to be detected by the photo detector system. This black to white presentation was stipulated to be cycled repeatedly in a squarewave with wavelengths of $0 \mathrm{msec}$ (or the fastest possible time specifiable) and $200 \mathrm{msec}$. This was done to determine the fastest possible delivery time of the software in the former case and the accuracy of the software, given a 100-msec screen duration, in the latter. Actual transition times achieved were averaged over the first stable 25 cycles. Note that because monitor refresh rates (the rate at which the raster gun refreshes the entire screen) did not synchronize with the timing requested of the software (i.e., the 100-msec duration requested did not coincide with a nonfractional number of screen refreshes), the times achieved are typical of those that would be encountered in a heterogeneous environment such as the Web, where there is little control over hardware settings on client systems.

Various characteristics of the computer systems tested are listed in Table 1. For each of the MacOS and Windows operating systems, a recent machine was tested, as well as an older, slower model, in an effort to provide some boundary information on systems that would likely be encountered on the Web. To the same end, performance under both Internet Explorer and Netscape Communicator was assessed. In all cases, the browser technology was up to date and near the most recent release. For information regarding the capabilities of various browser and operating system combinations, the reader is directed to http://browserwatch.internet.com/, the source for much of the information presented in this article regarding browser versions and their capabilities.

\section{WEB ANIMATION METHODS}

There are three broad approaches to Web animation: browser-implemented approaches, client-side programs, and browser extensions. Browser-implemented approaches present an animation by using code that is built into the browser's display capabilities. Animated GIF is the best- supported example of this approach. Included within an animated GIF file is a specification of the duration to present each image in the animation. Client-side programs are a second approach to Web animation. These animations rely on an interpreter's automatically being accessed by the browser when the Web user downloads a program embedded within a Web page. Execution of the program renders an animation on the client computer. Javascript/ JScript and Java animations are examples of client-side program solutions. Finally, browser plug-ins are a third method for delivering animations. This approach extends the capabilities of Web browsers so that they can present specialized content that has been retrieved from the server. Authorware, Flash, and Shockwave animations represent some examples of this approach.

The animation methods examined in the present paper will now be presented in turn, with browser-implemented methods (animated GIF) first, followed by client-side program approaches (Javascript/JScript and Java), and then specialized plug-in approaches (Flash and Authorware). In all cases, the Web pages and, where applicable, the source code that was used to produce these benchmarks can be found at http://survey.psy.buffalo.edu:8080/ speed/ in the appropriately labeled directory.

\section{Animated GIF}

The GIF was originally created to allow images to be downloaded and presented. Extensions to this format introduced later (the GIF89a convention) allowed multiple images to be included within a single file, along with information about order and how long each image should be presented. Browsers since Netscape Navigator 2.0 and Internet Explorer 1.0 have included the capability of decoding and presenting animated GIFs.

Several programs are available, both commercially and for free, that allow one to arrange the still images to be presented and to specify timing between frames. Such programs generally take as input image files that can be created using many different drawing or paint programs. Among the applications available for producing animated GIFs are the freeware and shareware GIF Builder and Graphic Converter 4.0 (Lemkesoft) under MacOS and, for Windows, commercial ventures such as GIF Animator (Ulead Systems) and GIF Construction Set (Alchemy Software). Many good tutorials about making animated GIFs are available on the Web, and each of the mentioned programs has excellent documentation.

Table 1

Computer Configurations Examined

\begin{tabular}{lrccccc}
\hline & $\begin{array}{c}\text { Clock } \\
\text { Speed } \\
\text { CPU }\end{array}$ & $\begin{array}{c}\text { Operating } \\
\text { System } \\
\text { Version }\end{array}$ & $\begin{array}{c}\text { RAM } \\
(\mathrm{MB})\end{array}$ & $\begin{array}{c}\text { Internet } \\
\text { Explorer } \\
\text { Version }\end{array}$ & $\begin{array}{c}\text { Netscape } \\
\text { Communicator } \\
\text { Version }\end{array}$ & $\begin{array}{c}\text { Monitor } \\
\text { Refresh Rate } \\
(\mathrm{Hz})\end{array}$ \\
\hline Power PC & & & & & & \\
$\quad$ Apple G4 & 400 & MacOS 9.04 & 128 & 5.01 & 4.6 & 67 \\
$\quad \begin{array}{c}\text { Apple 6100 } \\
\text { Windows }\end{array}$ & 60 & MacOS 8.51 & 70 & 5.01 & 4.7 & 67 \\
$\quad$ Compaq AMD & 500 & Windows 98 & 64 & 5.0 & 4.7 & 75 \\
Gateway Pentium & 75 & Windows 95 & 32 & 5.5 & 4.7 & 60 \\
\hline
\end{tabular}


As with the other Web animation methods, there are caveats associated with animated GIFs. First, recognize that such animations are presented without any control once the animation has begun-hence, there is no way to synchronize something like the collection of response times with these animations - whereas there would be such a capability using the methods that involve programming languages. Second, although generally not a worry, one may want to preload the entire GIF to ensure that it does not start being presented until all of the image components have been downloaded to the client computer. This can be done by loading the image early in the Web page in an image tag that specifies a picture of no size: $<$ IMG $\mathrm{SRC}=$ "animated.gif" WIDTH $=0 \mathrm{HEIGHT}=0>$. To cut down on transmission time for users with slow connections, various methods to decrease the size of such files are documented. For nonphotographic stimuli, animated GIF file sizes are generally not large to begin with.

A final concern about using animated GIFs is a legal one. The service provider CompuServe originally created the format, and subsequently the rights to the encoding algorithms and format were sold to Unisys. For many years, copyright issues were not pursued or noted, but as the Web became popular and GIF usage increased, Unisys began to view their legal rights as a potential source of revenue and began demanding royalties from programs that output GIF files. So, technically speaking, if the software one uses to create GIF files has not paid its licensing fees, any GIFs created with it are illegal (Inside Web Development, 2000). The reader is welcome to investigate whether the tools they use are lawfully legitimate.

A set of animated GIF files was created, with each stipulating one of the presentation durations examined. A part of the animated GIF standard is the specification of the duration to present each image. This is specified in hundredths of a second; hence, the resolution is specified on the order of centiseconds. The GIFs evaluated had settings of 0 and $10 \mathrm{csec}$ for each of the black and white frames, and the presentation was set to repeat indefinitely. The GIF was then simply loaded from a Web server by the browser on the platform to be tested.

\section{Javascript/JScript}

Javascript is a client-side scripting language originated by Netscape Communications that can be embedded within Web pages. Javascript-enabled browsers recognize the program code and execute it when rendering a Web page. Non-Javascript browsers simply ignore the embedded code. JScript is Microsoft's implementation and extension of Javascript, which differs in numerous subtle ways. Both Javascript and JScript are interpreted, with the interpreter being embedded within the Web browser program.

There are several caveats to using Javascript/JScript for Web-based animation. First, as one might guess, the two main browsers mentioned earlier are not equivalent in their implementation of these languages. Hence, one must ensure that any programs written will work on either browser; otherwise, error messages will be issued when the Web page is loaded. Second, even within different versions of the same browser, there are subtle differences. Third, there are frequently differences in program behavior across operating system implementations of the browsers. The resolution to this problem is to ensure that one's program works under different versions of the browsers and, if it does not, rewrite it so as to maximize proper behavior everywhere. Many sources of example Javascript/JScript code can be found on the Web, and frequently such code has been tested or modified to work with numerous system configurations. Reusing such code generally saves time and trouble, as compared with writing from scratch.

Browsers supporting Javascript/JScript style clientside scripting are required for this method of Web-based animation, and in addition, such implementations of the language must support the Image object, or else errors will ensue. Netscape products greater than Version 3.0 (under all operating systems except OS/2, which requires browser Version 2.02 or greater) support Javascript and the "Image object," as does Opera 3.0 and above. Versions of Internet Explorer 4.0 or greater support JScript and the Image object.

Javascript/JScript animation is accomplished by successively presenting images as quickly as possible. Preloading images (called caching) is an important step in ensuring that images are replaced quickly; otherwise, the presentation is delayed by the time needed to retrieve and decode the next image. Caching can be done within the Javascript/JScript program to ensure optimal performance. Through the use of timers, Javascript/JScript animation can ensue in a controlled fashion. In addition, as with the other programming approaches, additional code can be used to make animations contingent on other system events such as user actions.

Several Javascript/JScript programs that present graphical images (one black and one white) in successive 0 - or $100-\mathrm{msec}$ durations were created (modified from scripts found at http://www.schrenk.com/js/) and delivered from a Web server. Animation was accomplished by successively presenting the images for their specified duration (expressed in milliseconds), using Javascript/JScript timers.

\section{Java}

Java is a full-featured, platform-independent programming language that was developed by Sun Microsystems. Java applets are programs that are delivered over the Web to run on the client computer within the browser's program space. Graphical browsers since Version 3 of Navigator and Version 4 of Internet Explorer have contained some version of a Java interpreter. The manufacturer of the interpreter frequently varies with the browser and operating system, and some later versions of the browser allow the user to specify the interpreter to be used cooperatively under the browser program's command.

Although reference is made to the Java interpreter, Java gains its speed by executing programs that have been compiled into a universal byte-code that is interpreted on 
the client platform. Hence, although strictly interpreted, the code that is executed has been optimized and condensed into a simpler form. Even further speed gains can be accomplished by using a Java Just-In-Time (JIT) compiler on the client, which takes compiled byte-code and recompiles at run time for the target machine. Later versions of many browsers allow JIT compilers to be used in the place of standard Java interpreters.

The main drawback of Java involves the degree to which program code that works under one system configuration will work under others. Although originally touted as running on any platform after having been written, Java programs frequently misbehave in seemingly unpredictable ways when run on other systems or using other interpreters than those for which they were designed. The best resolution to this problem is simply to exhaustively test the code on a number of platforms and to write and rewrite it so as to maximize properly working code. A related problem involves variability in the way the program will actually look across different platforms. Again, the best resolution to this problem is heavy testing.

Java has been successfully used to deliver both tutorial (Francis et al., 2000; Stevenson et al., 1999) and original research (Hecht et al., 1999) experiments on the Web.

A simple Java applet was created to accomplish the display presentation by showing a repeating series of black and then white images, with the duration of the presentation stipulated in milliseconds ( 0 or 100 per frame). The timing for this sample was controlled by the client system's clock, accessed through the Java interpreter running under control of the Web browser tested.

\section{Flash}

Flash is a commercially designed (Macromedia) Web animation protocol that is implemented by the appropriate flash plug-in. Although commercially produced, the Flash format has become an open standard, which means that anybody can use it to create Flash-compatible movies. The Flash movie is interpreted by the plug-in and displayed through the viewer's Web browser. Both Macromedia's Flash and Adobe's LiveMotion programs write Flash movies primarily, and other products are beginning to provide the option of exporting this type of animation.

The Macromedia (2001) Web site makes claims that $96.4 \%$ of Web users operate Flash-enabled browsers. Although it is questionable whether the sample used for their survey is representative of Web users at large, it is the case that many of the more recent distributions of Web browsers and operating systems include the Flash plugin preinstalled. This format promises to reach a wide number of users and to provide an accessible alternative Web animation method. For users whose operating system is not supported by the Flash plug-in, or for those who do not have the plug-in, there is a freely available Java program that can present Flash movies.

Flash is designed for animation and allows minimal interactivity. For interactive animations, Macromedia designed the Shock wave animation system. Shockwave re- quires an additional plug-in and is a proprietary format. Shockwave animations are produced by Macromedia's Shockwave Internet Studio, as well as Macromedia Director 8.

Several Flash movies that present graphical images (one black and one white) in succession for 0 or $100 \mathrm{msec}$ each were created using Macromedia Flash 5.0. The requested frame rate was $67 \mathrm{~Hz}$. These animation files were then delivered to the browsers tested from a Web server. Only the plug-in version of the Flash player was evaluated. That is, no Java Flash player implementations were considered.

\section{Authorware}

Authorware is a commercially available graphical program development system (Macromedia). Although originally popular for delivering computer-based teaching and training, Authorware has been adopted by a devout group of users for a large number of general purpose tasks, including running demonstrations and experiments (McGraw et al., 2000a, 2000b; Williams et al., 1999). Because Authorware provides a method of delivering programs created with it over multiple Web platforms, animations created with this tool can be extended to the Web medium. For a client computer to be able to execute an Authorware program, the appropriate plug-in is needed. Currently, Authorware uses Macromedia's Authorware Web player plug-in, which is available for MacOS and Windows operating systems.

Caveats to using Authorware lie in the sophistication and system configurations of one's clients. First, as with Java and Javascript/JScript, there are version issues. In this case, however, rather than operating partially or unexpectedly, if the potential subject does not have the required version of the plug-in, he or she will be required to acquire it before proceeding. A second caveat is that a Web user who wishes to participate in an experiment must be fairly dedicated to go through the process of downloading the plug-in software (about 5.5 MB), quitting his or her Web browser and installing the software (requires $10 \mathrm{MB}$ of hard disk space and may require allocating greater memory than before installation), rerunning the browser, and revisiting the experiment's Web site. In addition, one faces the possibility that potential subjects will not be capable of doing the above, thereby causing a selection bias toward more computer literate or betterequipped subjects. A final caveat with Authorware is that although it provides a graphical programming environment that some find easier to use, it is nonetheless a programming language that requires learning to become adept. Furthermore, such skills are particular to Authorware and may be less likely to transfer to more mainstream programming languages like Java or $\mathrm{C}++$.

A simple program was created using Authorware 5.1 that would repeatedly present black and white images for 0 or $100 \mathrm{msec}$ each. The program was then packaged for the Web with a large package size to avoid delays in the animation while further code or graphics were retrieved 
over the network connection. This turned out to be an important step with regard to timing, because animations produced with the default Authorware settings reflected a large performance hit, owing to the simultaneous downloading of content while the Authorware code was executing, resulting in choppy animations and poor timing resolution on even the fastest systems. The appropriate files were uploaded to the Web server, and the Web server was configured to deliver Authorware content. Once this was achieved and once Web pages containing references to the programs created were made, these pages were accessed by the browsers used in the tests.

\section{RESULTS}

For each of the animation methods examined, a breakdown of the results is presented, with the data for the maximum system performance presented first ( 0 -msec durations) and the specified intervals (100-msec durations) presented second. Where difficulties arose, these are mentioned first, since they often give insight into the results.

For each of the system and software combinations examined, several types of summary information are presented. In an effort to keep discussion down, a description of the measures and their importance is now provided. First, the mean duration of one animation cycle is reported. In the case of fastest possible updating, this value gives insight into the average fastest possible animation cycle that this method can achieve. The standard deviation of the cycle yields insight into how consistent the method was at delivering a stable animation. This value represents how far errors were generally from the mean.

The second major measure reported is the average duration of the white image in the animation. Ideally, this is half of the duration of the animation cycle, because the software stipulates that white and black images should be presented for equal durations. Next, for the $100-\mathrm{msec}$ image duration condition, there is a column roughly summarizing the error level of the white image presentation in terms of the number of frames away from the target or requested number that were presented on average, along with the associated variability in this presentation. Hence a value of $3 \pm 1$ reveals that the method was, on average, off by three full frame presentations (full raster images) and that this generally varied by up to one full frame.

The third measure is the proportion of time that white images were presented, as compared with black images. Again, if the software is faithfully presenting all components of the animation, equal time should be provided to white and black images, yielding a proportion of .5 .

Finally, the modal cycle is presented. For this most often occurring sequence, the cycle duration and proportion of white to black image presentations are reported as before. This time, however, because the data are based on particular cycles, the duration of the white presentation is stipulated accurately in terms of the exact number of frames of the white image that was presented. Note that the duration can be achieved by taking the time per frame $(15 \mathrm{msec}$ for $60-\mathrm{Hz}, 16.667 \mathrm{msec}$ for $67 \mathrm{~Hz}$, and $13.333 \mathrm{msec}$ for $75-\mathrm{Hz}$ displays) and multiplying by the number of frames. Clearly, one desires the modal cycle to be an accurate animation, since this is the presentation that the majority of any data collected would be based on. The mode was computed separately for each of these measures, so the combination of values is not necessarily reflective of a single most frequently presented sequence.

\section{Animated GIF}

The animated GIF approach produced the results in Table 2 when it was set to update as quickly as possible. This should ideally uncover a lower limit of accuracy for the presentation method. The results suggest that for fast hardware, the method can achieve single image presentations as low as 2 frames on the Mac G4, with an upper bound of 7 frames on the Compaq. These image presentations generally varied by under 2 frames. For slower hardware, the data indicate a range of 7-15 frames per image of the animation, frequently off by $1-3$ frames.

The proportion of white to black in the animations was frequently off the .5 target, regardless of the platform. Modal cycle performance was in line with the means.

Table 2

Animated GIF With Updating Set to as Fast as Possible

\begin{tabular}{|c|c|c|c|c|c|c|c|c|}
\hline \multirow[b]{3}{*}{ System } & \multirow[b]{3}{*}{ Browser } & & & \multirow{3}{*}{$\begin{array}{c}\text { Duration } \\
\text { White }\end{array}$} & \multirow[b]{3}{*}{$\mathrm{W}: \mathrm{B}$} & \multicolumn{3}{|c|}{ Modal Cycle } \\
\hline & & \multicolumn{2}{|c|}{ Cycle Duration } & & & White & Cycle & \\
\hline & & $M$ & $S D$ & & & Frames & Duration & $\mathrm{W}: \mathrm{B}$ \\
\hline \multicolumn{9}{|l|}{ Power PC } \\
\hline \multirow[t]{2}{*}{ Apple G4 } & IE & 126.0 & 13.7 & 64.2 & .51 & 4 & 135 & .44 \\
\hline & NC & 66.6 & 7.6 & 31.8 & .48 & 2 & 60 & .50 \\
\hline \multirow[t]{2}{*}{ Apple 6100} & IE & 216.6 & 10.7 & 104.4 & .48 & 7 & 210 & .50 \\
\hline & $\mathrm{NC}$ & 291.6 & 41.3 & 110.4 & .38 & 7 & 300 & .35 \\
\hline \multicolumn{9}{|l|}{ Windows } \\
\hline \multirow[t]{2}{*}{ Compaq AMD } & IE & 199.0 & 30.3 & 114.0 & .58 & 8 & 215 & .50 \\
\hline & $\mathrm{NC}$ & 108.6 & 6.5 & 72.0 & .67 & 5 & 105 & .63 \\
\hline \multirow[t]{2}{*}{ Gateway Pentium } & IE & 198.5 & 38.8 & 97.3 & .49 & 7 & 216 & .50 \\
\hline & $\mathrm{NC}$ & 477.8 & 37.3 & 206.4 & .43 & 15 & 495 & .40 \\
\hline
\end{tabular}

Note-Durations are in milliseconds. IE refers to Internet Explorer, and NC to Netscape Communicator. $\mathrm{W}: \mathrm{B}$ is the ratio of white to black image presentation in the animation. White Frames refers to the number of white frames presented per cycle. 
The animated GIF results for files set to present each image for only $100 \mathrm{msec}(200 \mathrm{msec}$ per animation cycle) support the suggestion that accurate animations require at least 200-msec durations. As can be seen in Table 3, at these duration levels, the MacOS animations on fast hardware were, on average, from one to two frames longer than stipulated, and the Windows animations were up to four frames off target. On top of this, variation was generally under one frame under MacOS and under two on Windows, regardless of the browser used.

Internet Explorer produced very good results on slower hardware- even more accurate than those on faster systems. Netscape Communicator's performance, on the other hand, was extremely poor on slower systems, taking between two and three times the requested duration to present an animation. In addition, the presentation timing was highly variable on the slower Macintosh Netscape Communicator combination, and the balance of white to black presentation under Windows was inaccurate. Perhaps, rather than using a system clock for updating, Netscape Communicator is using to loop to implement timing. Examination of the Netscape Communicator source code could give further insight if one were so inclined. Again, the modal cycle performance was representative of the mean animation statistics.

\section{Javascript/JScript Animation}

The Javascript/JScript animation results showed this approach to be surprisingly accurate. Table 4 presents the results when the Javascript/JScript timer was set to $0 \mathrm{msec}$-requiring an update as fast as possible. The data show that for fast hardware, the method can achieve single image presentations with durations as low as a single frame on the Mac G4. On the Compaq, about four frames per image presentation were achieved. For slower hardware, the data indicate a range of four to eight frames per animation image. This suggests that presentation durations lower than about $120 \mathrm{msec}$ will be inaccurate overall. Remarkably, although Internet Explorer on the Apple 6100 lengthened the duration for which it showed each image relative to the faster $\mathrm{G} 4$, it was perfectly synchronized with the display.

Variability was low throughout, demonstrating that the Javascript/JScript animation was about as consistent as possible, given the mismatch between specified timing and the monitor's vertical refresh rate. Both browsers varied by less than a single frame in general, except for Netscape Communicator on the slowest PC hardware.

Both Internet Explorer and Netscape Communicator did a good job of balancing the distribution of the images throughout the cycle; however, as with animated GIFs, Netscape Communicator did more poorly when it was running on the slower systems.

Results for the Javascript/JScript animation specifying 100-msec presentation of each animation image appear in Table 5. In general, the animations were fairly accurate under Internet Explorer, regardless of the hardware. On the more powerful systems, images were, on average, presented less than a single frame longer than specifiederror attributable to the mismatch between the software settings and the monitor refresh rate. Even on the slower Apple 6100 , the software was generally off only by a little more than one frame.

On all systems except the G4, each of the animation images was presented at least 50\% longer than specified in the software when run under Netscape Communicator. This problem was present regardless of whether the system was powerful or not. In addition, variability was low for Internet Explorer regardless of the client system examined, whereas variability for Netscape Communicator was related to system speed. Given the earlier results with animated GIFs, it is becoming apparent that Netscape Communicator is not the browser of choice for accurate animations.

\section{Java}

The Java animation results suggest that durations around $100 \mathrm{msec}$ should be achievable by this method regardless of the hardware used. Durations for a single animation image in the fastest possible updating conditions

Table 3 Animated GIF With Settings of $100 \mathrm{msec}$ per Image

\begin{tabular}{|c|c|c|c|c|c|c|c|c|c|}
\hline \multirow[b]{3}{*}{ System } & \multirow[b]{3}{*}{ Browser } & & & \multirow{3}{*}{$\begin{array}{c}\text { Duration } \\
\text { White }\end{array}$} & \multirow[b]{3}{*}{ Error } & \multirow[b]{3}{*}{$\mathrm{W}: \mathrm{B}$} & \multicolumn{3}{|c|}{ Modal Cycle } \\
\hline & & \multicolumn{2}{|c|}{ Cycle Duration } & & & & White & Cycle & \\
\hline & & $M$ & $S D$ & & & & Frames & Duration & $\mathrm{W}: \mathrm{B}$ \\
\hline \multicolumn{10}{|l|}{ Power PC } \\
\hline \multirow[t]{2}{*}{ Apple G4 } & IE & 221.2 & 11.1 & 111.0 & $1 \pm 1$ & .50 & - & - & .50 \\
\hline & $\mathrm{NC}$ & 233.4 & 7.6 & 112.8 & $1 \pm 1$ & .48 & 8 & 240 & .50 \\
\hline \multirow[t]{2}{*}{ Apple 6100} & IE & 216.7 & 9.6 & 108.0 & $1 \pm 1$ & .50 & 7 & 212 & .50 \\
\hline & $\mathrm{NC}$ & 480.5 & 153.6 & 229.8 & $9 \pm 10$ & .45 & 13 & 450 & .43 \\
\hline \multicolumn{10}{|l|}{ Windows } \\
\hline \multirow[t]{2}{*}{ Compaq AMD } & IE & 199.7 & 28.9 & 111.6 & $1 \pm 2$ & .50 & 8 & 213 & .50 \\
\hline & $\mathrm{NC}$ & 254.0 & 28.9 & 136.8 & $3 \pm 2$ & .54 & 8 & 280 & .38 \\
\hline \multirow[t]{2}{*}{ Gateway Pentium } & IE & 201.0 & 25.8 & 98.0 & $0 \pm 2$ & .48 & 7 & 216 & .54 \\
\hline & $\mathrm{NC}$ & 665.4 & 12.2 & 281.4 & $11 \pm 1$ & .42 & 19 & 667 & .38 \\
\hline
\end{tabular}

Note-IE refers to Internet Explorer, and NC to Netscape Communicator. W:B is the ratio of white to black image presentation in the animation. Error is in average number of frames from the target \pm 1 standard deviation from the target. Durations are in milliseconds. 
Table 4

Javascript/JScript Animations Updating as Fast as Possible

\begin{tabular}{|c|c|c|c|c|c|c|c|c|}
\hline \multirow[b]{3}{*}{ System } & \multirow[b]{3}{*}{ Browser } & \multirow{2}{*}{\multicolumn{2}{|c|}{ Cycle Duration }} & \multirow{3}{*}{$\begin{array}{c}\text { Duration } \\
\text { White }\end{array}$} & \multirow[b]{3}{*}{$\mathrm{W}: \mathrm{B}$} & \multicolumn{3}{|c|}{ Modal Cycle } \\
\hline & & & & & & White & Cycle & \\
\hline & & $M$ & $S D$ & & & Frames & Duration & $\mathrm{W}: \mathrm{B}$ \\
\hline \multicolumn{9}{|l|}{ Power PC } \\
\hline \multirow[t]{2}{*}{ Apple G4 } & IE & 30.6 & 8.1 & 15.0 & .53 & 1 & 30 & .50 \\
\hline & $\mathrm{NC}$ & 66.6 & 7.6 & 34.2 & .51 & 3 & 75 & .50 \\
\hline \multirow{2}{*}{ Apple 6100} & IE & 240.0 & 0.0 & 120.0 & .50 & 8 & 240 & .50 \\
\hline & $\mathrm{NC}$ & 127.2 & 8.8 & 63.0 & .50 & 4 & 135 & .44 \\
\hline \multicolumn{9}{|l|}{ Windows } \\
\hline \multirow[t]{2}{*}{ Compaq AMD } & IE & 108.6 & 5.3 & 56.0 & .52 & 4 & 106 & .50 \\
\hline & $\mathrm{NC}$ & 109.1 & 5.7 & 53.9 & .49 & 4 & 106 & .50 \\
\hline \multirow[t]{2}{*}{ Gateway Pentium } & IE & 250.3 & 4.4 & 128.0 & .51 & 8 & 249 & .54 \\
\hline & $\mathrm{NC}$ & 112.9 & 14.9 & 57.3 & .51 & 3 & 116 & .50 \\
\hline
\end{tabular}

Note-Durations are in milliseconds. IE refers to Internet Explorer, and NC to Netscape Communicator. $\mathrm{W}: \mathrm{B}$ is the ratio of white to black image presentation in the animation. White Frames refers to the number of white frames presented per cycle.

were between $30 \mathrm{msec}$ on the fastest systems and $70 \mathrm{msec}$ on the slowest (see Table 6). Entire animation cycles were, at maximum, about $110 \mathrm{msec}$.

Tempering these positive results, variability was fairly high with lows of $6 \mathrm{msec}$ (under one frame) on faster Windows systems, but up to $80 \mathrm{msec}$ (under six frames) on slower Mac hardware. Macintosh systems were in general more variable, as is the case with custom programming as well, owing to the MacOS's lack of true multitasking. In addition, the proportion of white to black image presentation was slightly skewed. Modally, images were presented for durations of from one to four screen refreshes.

Table 7 contains the results of stipulating animation frame durations of $100 \mathrm{msec}$. Performance was consistent regardless of whether the hardware tested was fast or slow. Windows systems were, on average, within one screen refresh of their target duration for the presentation of the white animation frame, and MacOS systems were generally within about three screen refreshes of their target. Variability was low regardless of the system, browser, or hardware combination examined, with the complete animation being off by under one frame. As with fast updating, MacOS performance was slightly less accurate than Windows, and the proportion of white to black in the image presentation was somewhat off. No systematic differences between Internet Explorer and Netscape Communicator were obvious.

\section{Flash Animation}

Despite claims by Macromedia that $96.4 \%$ of browsers are Flash equipped, the MacOS systems still required a download and install of the plug-in. This aside, the accuracy data obtained with the Flash plug-in were mixed. Capabilities across the different systems are revealed in Table 8 in the data with the fastest possible animation updating. Updating is extremely fast with the fast Mac system, but much slower on slower Mac systems and the Windows systems. Speed of image presentation on the G4 was down to a single frame. The lower bound of the faster PC system was between four and eight frames, depending on the browser used. Upper bounds on animation updating come from the slower systems, with 10-11 screen refreshes on the Mac 6100 and 15 on the Gateway system. This suggests a lower bound on timing accuracy of at least $250 \mathrm{msec}$.

Table 5

Javascript/JScript Animations With Settings of 100 msec per Image

\begin{tabular}{|c|c|c|c|c|c|c|c|c|c|}
\hline \multirow[b]{3}{*}{ System } & \multirow[b]{3}{*}{ Browser } & & & \multirow{3}{*}{$\begin{array}{c}\text { Duration } \\
\text { White }\end{array}$} & \multirow[b]{3}{*}{ Error } & \multirow[b]{3}{*}{$\mathrm{W}: \mathrm{B}$} & \multicolumn{3}{|c|}{ Modal Cycle } \\
\hline & & \multicolumn{2}{|c|}{ Cycle Duration } & & & & White & Cycle & \\
\hline & & $M$ & $S D$ & & & & Frames & Duration & $\mathrm{W}: \mathrm{B}$ \\
\hline \multicolumn{10}{|l|}{ Power PC } \\
\hline \multirow[t]{2}{*}{ Apple G4 } & IE & 205.6 & 6.8 & 103.2 & $0 \pm 1$ & .50 & 7 & 210 & .50 \\
\hline & $\mathrm{NC}$ & 232.8 & 7.6 & 117.0 & $1 \pm 1$ & .50 & 8 & 240 & .50 \\
\hline \multirow[t]{2}{*}{ Apple 6100} & IE & 240.0 & 0.0 & 120.0 & $1 \pm 0$ & .50 & 8 & 240 & .50 \\
\hline & $\mathrm{NC}$ & 312.0 & 58.4 & 150.0 & $3 \pm 4$ & .49 & 10 & 302 & .50 \\
\hline \multicolumn{10}{|l|}{ Windows } \\
\hline \multirow[t]{2}{*}{ Compaq AMD } & IE & 220.0 & 6.8 & 113.1 & $1 \pm 1$ & .51 & 8 & 213 & .50 \\
\hline & $\mathrm{NC}$ & 331.4 & 4.3 & 167.0 & $5 \pm 1$ & .50 & 13 & 333 & .52 \\
\hline \multirow[t]{2}{*}{ Gateway Pentium } & IE & 330.0 & 5.6 & 163.3 & $5 \pm 1$ & .50 & 10 & 332 & .50 \\
\hline & $\mathrm{NC}$ & 333.5 & 11.8 & 168.6 & $5 \pm 1$ & .51 & 10 & 332 & .50 \\
\hline
\end{tabular}

Note-IE refers to Internet Explorer, and NC to Netscape Communicator. W:B is the ratio of white to black image presentation in the animation. Error is in average number of frames from the target \pm 1 standard deviation from the target. Durations are in milliseconds. 
Table 6

Java Animations Updating as Fast as Possible

\begin{tabular}{|c|c|c|c|c|c|c|c|c|}
\hline \multirow[b]{3}{*}{ System } & \multirow[b]{3}{*}{ Browser } & & & \multirow{3}{*}{$\begin{array}{c}\text { Duration } \\
\text { White }\end{array}$} & \multirow[b]{3}{*}{$\mathrm{W}: \mathrm{B}$} & \multicolumn{3}{|c|}{ Modal Cycle } \\
\hline & & \multicolumn{2}{|c|}{ Cycle Duration } & & & White & Cycle & \\
\hline & & $M$ & $S D$ & & & Frames & Duration & $\mathrm{W}: \mathrm{B}$ \\
\hline \multicolumn{9}{|l|}{ Power PC } \\
\hline \multirow[t]{2}{*}{ Apple G4 } & IE & 49.2 & 30.2 & 29.4 & .54 & 1 & 30 & .50 \\
\hline & $\mathrm{NC}$ & 95.4 & 18.3 & 49.2 & .51 & 3 & 90 & .50 \\
\hline \multirow[t]{2}{*}{ Apple 6100} & IE & 84.6 & 7.4 & 42.6 & .50 & 3 & 90 & .50 \\
\hline & $\mathrm{NC}$ & 107.4 & 79.3 & 63.0 & .54 & 3 & 90 & .50 \\
\hline \multicolumn{9}{|l|}{ Windows } \\
\hline \multirow[t]{2}{*}{ Compaq AMD } & IE & 110.1 & 5.7 & 53.3 & .49 & 4 & 107 & .50 \\
\hline & $\mathrm{NC}$ & 110.1 & 5.7 & 53.9 & .49 & 4 & 107 & .50 \\
\hline \multirow[t]{2}{*}{ Gateway Pentium } & IE & 116.6 & 31.5 & 67.3 & .57 & $3 / 4$ & 116 & .58 \\
\hline & $\mathrm{NC}$ & 109.9 & 8.3 & 56.0 & .51 & 3 & 116 & .51 \\
\hline
\end{tabular}

Note-Durations are in milliseconds. IE refers to Internet Explorer, and NC to Netscape Communicator. $\mathrm{W}: \mathrm{B}$ is the ratio of white to black image presentation in the animation. White Frames refers to the number of white frames presented per cycle.

Variability was low for faster systems, suggesting that presentation was as good as it could be, given the mismatch of the monitor refresh and the software settings. Variability on slower systems was markedly increased, with frames frequently off by as much as eight frames. In addition, whereas faster systems presented a temporally balanced animation sequence, Flash disproportionately biased the presentation of certain frames on slower systems so that there was a greater proportion of the white than of the black image. If this were an experiment, the implication would be that one of these two durations was generally too long and the other too short.

There was not much difference based on the browser interfaced to the plug-in, suggesting that the Flash animation method was at the source of variation in these data.

The results of the Flash animations specifying 100-msec presentations of each image show similar trends to those with the fastest possible updating, as can be seen in Table 9. On average, animation images were presented for one to two frames longer than specified in the software on fast systems, although variability around this error was low. This was the case regardless of the browser used.
Deterioration in accuracy was marked in slower systems, with durations of presentation two to three times that stipulated in the software-that is, two orders of magnitude in the error! Variability was also generally high under these conditions - from a low of one screen refresh on the slower Pentium system to a high of nine frames on the older Mac system with Internet Explorer. In addition, the animation was again biased toward presenting the white frame for a substantially longer period of time than the black frame, regardless of the browser used.

\section{Authorware}

A number of problems were encountered when testing the Authorware animation. The Authorware Web Player had to be downloaded and installed separately for each browser and each system. Even after numerous installation attempts with Netscape Communicator on the G4 (all of which indicated no errors in installation), the Authorware Web Player failed to launch, and the browser failed to indicate that it could handle Authorware animations. As a result, there are no data reported for this system and browser combination.

Table 7

Java Animations With Settings of 100 msec per Image

\begin{tabular}{|c|c|c|c|c|c|c|c|c|c|}
\hline \multirow[b]{3}{*}{ System } & \multirow[b]{3}{*}{ Browser } & & & \multirow{3}{*}{$\begin{array}{c}\text { Duration } \\
\text { White }\end{array}$} & \multirow[b]{3}{*}{ Error } & \multirow[b]{3}{*}{$\mathrm{W}: \mathrm{B}$} & \multicolumn{3}{|c|}{ Modal Cycle } \\
\hline & & \multicolumn{2}{|c|}{ Cycle Duration } & & & & White & Cycle & \\
\hline & & $M$ & $S D$ & & & & Frames & Duration & $\mathrm{W}: \mathrm{B}$ \\
\hline \multicolumn{10}{|l|}{ Power PC } \\
\hline \multirow[t]{2}{*}{ Apple G4 } & IE & 207.6 & 12.8 & 111.6 & $1 \pm 1$ & .54 & 7 & 210 & .50 \\
\hline & $\mathrm{NC}$ & 293.4 & 10.7 & 148.2 & $3 \pm 1$ & .51 & 10 & 285 & .53 \\
\hline \multirow[t]{2}{*}{ Apple 6100} & $\mathrm{IE}$ & 250.8 & 6.9 & 125.4 & $2 \pm 0$ & .50 & 8 & 255 & $.47 / .53$ \\
\hline & $\mathrm{NC}$ & 284.4 & 14.7 & 143.4 & $3 \pm 4$ & .50 & 9 & 285 & .53 \\
\hline \multicolumn{10}{|l|}{ Window } \\
\hline \multirow[t]{2}{*}{ Compaq AMD } & IE & 224.0 & 16.5 & 112.0 & $1 \pm 1$ & .50 & 8 & 213 & .50 \\
\hline & $\mathrm{NC}$ & 221.8 & 14.0 & 109.3 & $1 \pm 1$ & .49 & 8 & 213 & .50 \\
\hline \multirow[t]{2}{*}{ Gateway Pentium } & IE & 224.4 & 14.2 & 112.7 & $1 \pm 1$ & .50 & 7 & 216 & .46 \\
\hline & $\mathrm{NC}$ & 222.5 & 14.2 & 114.0 & $1 \pm 1$ & .51 & 7 & 216 & .54 \\
\hline
\end{tabular}

Note-IE refers to Internet Explorer, and NC to Netscape Communicator. W:B is the ratio of white to black image presentation in the animation. Error is in average number of frames from the target \pm 1 standard deviation from the target. Durations are in milliseconds. 
Table 8

Flash Animations With Updating Set to as Fast as Possible

\begin{tabular}{|c|c|c|c|c|c|c|c|c|}
\hline \multirow[b]{3}{*}{ System } & \multirow[b]{3}{*}{ Browser } & & & \multirow{3}{*}{$\begin{array}{c}\text { Duration } \\
\text { White }\end{array}$} & \multirow[b]{3}{*}{$\mathrm{W}: \mathrm{B}$} & \multicolumn{3}{|c|}{ Modal Cycle } \\
\hline & & \multicolumn{2}{|c|}{ Cycle Duration } & & & White & Cycle & \\
\hline & & $M$ & $S D$ & & & Frames & Duration & $\mathrm{W}: \mathrm{B}$ \\
\hline \multicolumn{9}{|l|}{ Power PC } \\
\hline \multirow[t]{2}{*}{ Apple G4 } & IE & 27.6 & 7.1 & 15.0 & .59 & 1 & 30 & .50 \\
\hline & $\mathrm{NC}$ & 26.4 & 6.5 & 15.0 & .62 & 1 & 30 & .50 \\
\hline \multirow[t]{2}{*}{ Apple 6100} & IE & 228.6 & 79.2 & 160.8 & .74 & 11 & 215 & .77 \\
\hline & $\mathrm{NC}$ & 189.2 & 16.3 & 160.8 & .85 & 10 & 180 & .83 \\
\hline \multicolumn{9}{|l|}{ Windows } \\
\hline \multirow{2}{*}{ Compaq AMD } & IE & 218.3 & 5.9 & 107.7 & .49 & 8 & 214 & .50 \\
\hline & $\mathrm{NC}$ & 108.6 & 6.5 & 56.0 & .52 & 4 & 105 & .51 \\
\hline \multirow[t]{2}{*}{ Gateway Pentium } & IE & 309.6 & 15.4 & 257.3 & .83 & 15 & 315 & .85 \\
\hline & $\mathrm{NC}$ & 477.2 & 41.0 & 186.1 & .39 & 15 & 500 & .40 \\
\hline
\end{tabular}

Note-Durations are in milliseconds. IE refers to Internet Explorer, and NC to Netscape Communicator. $\mathrm{W}: \mathrm{B}$ is the ratio of white to black image presentation in the animation. White Frames refers to the number of white frames presented per cycle.

The Authorware player seemed to take a fair bit of time to initialize on most of the systems examined. It was not uncommon for the system to take 20-30 sec before launching the window leading to the animation, and noticeable delays were encountered throughout on the slower systems.

In theory, Authorware has an intelligent stream manager that is designed to get the animation started quickly and to conduct further interactions with the Web server in the background in an optimized manner. To use the streamer requires that browsers support streaming content and that the Web server support the installation of the Authorware Advanced Streamer. To do this was a greater undertaking than the author wished to attempt. The present tests used the simple version of the technology, so perhaps with further work the timing achieved could be better than the values presented. However, it should be noted that the animations were constructed with the stipulation that they be loaded in full before execution, so any inaccuracies are unlikely to be reduced by use of the Advanced Streamer.

An additional problem encountered was that, on all of the MacOS systems on which it worked, regardless of power or memory, the player ran out of memory only part way into the animation. Nonetheless, the data are presented omitting this glitch.

From an examination of the data in Table 10, one can gain insight into the level of accuracy that the software is capable of delivering when specified to update the animation as quickly as possible. Although the player did a fairly good job of balancing the ratio of time that each image was presented, regardless of the power of the computer system, there was a clear performance difference for slow versus fast technology.

Slower systems were extremely slow to present an animation cycle. The average cycle was over $800 \mathrm{msec}$. This provides accuracy for a single frame of about half a second, more than double the least accurate updating of the other methods. In addition, the updating was highly variable - with most updates generally varying by $2-25$ frames or 30-400 msec. On slower systems, Netscape Communicator seemed to interface with the Web Player better than did Internet Explorer, regardless of platform.

With faster technology, performance was markedly improved, with the Windows implementation of the Web

Table 9

Flash Animations With Settings of $100 \mathrm{msec}$ per Image

\begin{tabular}{|c|c|c|c|c|c|c|c|c|c|}
\hline \multirow[b]{3}{*}{ System } & \multirow[b]{3}{*}{ Browser } & & & \multirow{3}{*}{$\begin{array}{c}\text { Duration } \\
\text { White }\end{array}$} & \multirow[b]{3}{*}{ Error } & \multirow[b]{3}{*}{$\mathrm{W}: \mathrm{B}$} & \multicolumn{3}{|c|}{ Modal Cycle } \\
\hline & & \multicolumn{2}{|c|}{ Cycle Duration } & & & & White & Cycle & \\
\hline & & $M$ & $S D$ & & & & Frames & Duration & $\mathrm{W}: \mathrm{B}$ \\
\hline \multicolumn{10}{|l|}{ Power PC } \\
\hline \multirow[t]{2}{*}{ Apple G4 } & IE & 232.8 & 7.7 & 118.8 & $1 \pm 1$ & .51 & 8 & 240 & .50 \\
\hline & $\mathrm{NC}$ & 232.2 & 7.7 & 120.0 & $1 \pm 1$ & .52 & 8 & 225 & .53 \\
\hline \multirow[t]{2}{*}{ Apple 6100} & IE & 334.2 & 135.0 & 270.0 & $11 \pm 9$ & .83 & 16 & 285 & .84 \\
\hline & $\mathrm{NC}$ & 274.2 & 21.5 & 276.0 & $12 \pm 1$ & 1.00 & 18 & 280 & .96 \\
\hline \multicolumn{10}{|l|}{ Windows } \\
\hline \multirow[t]{2}{*}{ Compaq AMD } & IE & 219.8 & 6.2 & 111.5 & $1 \pm 1$ & .51 & 8 & 213 & .50 \\
\hline & $\mathrm{NC}$ & 220.6 & 7.9 & 113.6 & $1 \pm 1$ & .52 & 8 & 213 & .50 \\
\hline \multirow[t]{2}{*}{ Gateway Pentium } & IE & 385.1 & 11.0 & 333.3 & $14 \pm 1$ & .87 & 20 & 381 & .88 \\
\hline & $\mathrm{NC}$ & 382.6 & 7.3 & 332.7 & $14 \pm 1$ & .87 & 20 & 381 & .88 \\
\hline
\end{tabular}

Note-IE refers to Internet Explorer, and NC to Netscape Communicator. W:B is the ratio of white to black image presentation in the animation. Error is in average number of frames from the target \pm 1 standard deviation from the target. Durations are in milliseconds. 
Table 10

Authorware Animations With Updating Set to as Fast as Possible

\begin{tabular}{|c|c|c|c|c|c|c|c|c|}
\hline \multirow[b]{3}{*}{ System } & \multirow[b]{3}{*}{ Browser } & & & \multirow{3}{*}{$\begin{array}{c}\text { Duration } \\
\text { White }\end{array}$} & \multirow[b]{3}{*}{$\mathrm{W}: \mathrm{B}$} & \multicolumn{3}{|c|}{ Modal Cycle } \\
\hline & & \multicolumn{2}{|c|}{ Cycle Duration } & & & White & Cycle & \\
\hline & & $M$ & $S D$ & & & Frames & Duration & $\mathrm{W}: \mathrm{B}$ \\
\hline \multicolumn{9}{|l|}{ Power PC } \\
\hline \multirow{2}{*}{ Apple G4 } & IE & 85.2 & 11.2 & 43.2 & .51 & 3 & 90 & .50 \\
\hline & $\mathrm{NC}$ & - & - & - & - & - & - & - \\
\hline \multirow[t]{2}{*}{ Apple 6100} & IE & 851.0 & 171.7 & 444.6 & .51 & $25 / 27$ & 375 & .50 \\
\hline & $\mathrm{NC}$ & 537.6 & 28.6 & 265.8 & .50 & $17 / 18$ & $525 / 540$ & .50 \\
\hline \multicolumn{9}{|l|}{ Windows } \\
\hline \multirow[t]{2}{*}{ Compaq AMD } & IE & 42.6 & 8.4 & 17.6 & .52 & 1 & 50 & .51 \\
\hline & $\mathrm{NC}$ & 47.3 & 9.4 & 18.1 & .48 & 1 & 50 & .33 \\
\hline \multirow[t]{2}{*}{ Gateway Pentium } & IE & $1,023.9$ & 412.0 & 558.7 & .52 & 29 & 929 & .52 \\
\hline & $\mathrm{NC}$ & 925.8 & 57.2 & 466.7 & .50 & 31 & 945 & .49 \\
\hline
\end{tabular}

Note-Durations are in milliseconds. IE refers to Internet Explorer, and NC to Netscape Communicator. $\mathrm{W}: \mathrm{B}$ is the ratio of white to black image presentation in the animation. White Frames refers to the number of white frames presented per cycle.

Player faring better than the MacOS version. Variability was also down to under a single frame in general, indicating the importance of having a fast system for this method.

These mixed data suggest wildly different accuracy levels for this method from fast versus slow hardware and Windows versus Macintosh operating systems. With a fast system, accuracy is about as good as it can be, given a mismatch to the raster scan of the monitor, and the method would be expected to be fairly accurate for durations over $100 \mathrm{msec}$. On slower systems however, the Authorware player degraded rapidly, with durations of under a second unlikely to be properly presented.

A test of these claims came directly from the animation designed to present each animation frame for only $100 \mathrm{msec}$. As would be expected from the results of Table 10, the Web Player fared poorly on slower systemspresenting a 100-msec image for approximately $500 \mathrm{msec}$. Again, as can be seen from Table 11, variability was high, with presentations frequently within four frames on older hardware.

With fast hardware, animation frames that were to be presented for $100 \mathrm{msec}$ were presented, on average, about $25 \mathrm{msec}$ longer (one or two frames). Variation was generally low, within about a single frame. There were no great differences in performance between the browsers in which these Authorware animations were presented.

\section{DISCUSSION}

As the results from the many tests of presentation potential and accuracy revealed, error, in terms of deviation from stipulated durations and variability, is generally high across different hardware, browser, operating system, and Web animation methods. Different methods demonstrated different patterns of variability across subsets of these variables. Table 12 provides a summary of the combinations of these variables that, for each method examined, were found to produce trends toward lower than baseline performance. An examination of the table reveals that all of the methods except Java performed more poorly on slower hardware than on faster hardware. Other than this general trend, browser and operating system only raised problems in particular combinations. Netscape Communicator was generally inferior to Internet Explorer for Animated GIF and Javascript/JScript animations, particularly for GIF animation on slow systems

Table 11

Authorware Animations With Settings of $100 \mathrm{msec}$ per Image

\begin{tabular}{|c|c|c|c|c|c|c|c|c|c|}
\hline \multirow[b]{3}{*}{ System } & \multirow[b]{3}{*}{ Browser } & & & \multirow{3}{*}{$\begin{array}{c}\text { Duration } \\
\text { White }\end{array}$} & \multirow[b]{3}{*}{ Error } & \multirow[b]{3}{*}{ W:B } & \multicolumn{3}{|c|}{ Modal Cycle } \\
\hline & & \multicolumn{2}{|c|}{ Cycle Duration } & & & & White & Cycle & \\
\hline & & $M$ & $S D$ & & & & Frames & Duration & $\mathrm{W}: \mathrm{B}$ \\
\hline \multicolumn{10}{|l|}{ Power PC } \\
\hline \multirow[t]{2}{*}{ Apple G4 } & IE & 267.6 & 19.2 & 131.4 & $2 \pm 1$ & .49 & 9 & 270 & .50 \\
\hline & $\mathrm{NC}$ & - & - & - & - & - & - & - & - \\
\hline \multirow{2}{*}{ Apple 6100} & IE & 998.3 & 46.8 & 494.4 & $26 \pm 3$ & .50 & 33 & 975 & .49 \\
\hline & $\mathrm{NC}$ & 723.0 & 26.7 & 406.7 & $20 \pm 2$ & .51 & 24 & 720 & .50 \\
\hline \multicolumn{10}{|l|}{ Windows } \\
\hline \multirow[t]{2}{*}{ Compaq AMD } & IE & 239.1 & 8.2 & 120.7 & $1 \pm 1$ & .50 & 7 & 233 & .50 \\
\hline & $\mathrm{NC}$ & 238.4 & 8.0 & 120.7 & $1 \pm 1$ & .51 & 7 & 233 & .50 \\
\hline \multirow[t]{2}{*}{ Gateway Pentium } & IE & $1,107.4$ & 76.7 & 550.7 & $32 \pm 6$ & .50 & 85 & 1127 & .52 \\
\hline & $\mathrm{NC}$ & $1,071.6$ & 63.8 & 539.3 & $31 \pm 5$ & .50 & 30 & 1011 & .49 \\
\hline
\end{tabular}

Note-IE refers to Internet Explorer, and NC to Netscape Communicator. W:B is the ratio of white to black image presentation in the animation. Error is in average number of frames from the target \pm 1 standard deviation from the target. Durations are in milliseconds. 
Table 12

Summary of Browser, Operating System (OS), and Hardware Combinations Producing Notably Poor Performances as a Function of Animation Method

\begin{tabular}{|c|c|c|c|c|c|c|c|}
\hline Method & $\begin{array}{c}\text { Speed of } \\
\text { System }\end{array}$ & Browser & OS & $\begin{array}{c}\text { Speed } \times \\
\text { OS }\end{array}$ & $\begin{array}{l}\text { Speed } \times \\
\text { Browser }\end{array}$ & $\begin{array}{c}\text { Browser } \\
\times \mathrm{OS} \\
\end{array}$ & $\begin{array}{c}\text { Speed } \times \text { Browser } \\
\times \text { OS } \\
\end{array}$ \\
\hline Animated GIF & slow & $\mathrm{NC}$ & & slow, NC & & & \\
\hline Javascript/JScript & slow & $\mathrm{NC}$ & & & & & slow, NC, MacOS \\
\hline Java & & & & & & & $\mathrm{NC}, \mathrm{MacOS}$ \\
\hline Flash & slow & & & & & & slow, IE, MacOS \\
\hline Authorware & slow & & & slow, Windows & slow, IE & & \\
\hline
\end{tabular}

Note-IE refers to Internet Explorer, and NC to Netscape Communicator.

and for Javascript/JScript on slower Macs. Internet Explorer was inferior to Netscape Communicator for Flash on slower Macs and for Authorware on slower systems in general. Authorware animations were executed exceptionally poorly on slower Windows systems, and Java fared poorest with Netscape Communicator under MacOS, regardless of the hardware.

A summary of the poorest performance observed, evaluated in terms of the cycle duration and associated standard deviation, as well as the modal performance for both fast and slow systems considered separately, is presented for each animation method in Tables 13 and 14. These data are presented in this manner because system speed was the single factor observed to affect almost all of the animation types. In addition, the poorest performance indicates the worst case results that can be expected to contaminate data from an animation method. Table 13 summarizes the data acquired for animations set to update as quickly as possible, and Table 14 summarizes the data for animations with image durations set at $100 \mathrm{msec}$.

A quick scan down the cycle duration columns of either table reveals that only Java and Javascript/JScript produced durations that were largely unaffected by system speed and that these two methods were associated with the greatest accuracy and the lowest presentation times, although Java's accuracy was lower under MacOS than under Windows. Even for these methods, accuracy was off by about a third of the timed duration when animation frame durations were set to $100 \mathrm{msec}$ (Table 14). Although these represent worst case conditions, as can be seen from Tables 2-11, inaccuracy was the norm.

Turning to variability related to cycle duration, Javascript/JScript, Java, and Flash produced the least vari- able presentation for both fast updating (Table 13) and fixed duration animations (Table 14). Only the variability of Java was unaffected by system speed when a fixed duration animation was examined. Both Java and Javascript/JScript modal performance on slow systems was good, and modal performance of Java on fast systems was fairly good.

The performance of all animation methods except Java was dependent on system speed, which is a worrisome finding when one considers that the World-Wide Web is a heterogeneous environment in which one is guaranteed to encounter a wide range of different systems and, consequently, different system speeds.

\section{Is Animation Presentation Really This Inaccurate and Variable?}

Yes. In fact, these are likely to be conservative data, since they were collected on systems that were running no other applications or background processes beyond those required by the operating system. In addition, the communication links of these systems were all fast Ethernet. World-Wide Web users cannot be guaranteed to be running only their browsers (e.g., consider all of those system tray applications on your Windows machine, or extensions on your Macintosh that start up each time you boot your system), and their connection speeds are unlikely to be as fast as those on the systems examined. Insofar as connection speed interacts with these methods (i.e., the downloading of animation frames or the communication of other information in the background), it will interact with the timing achieved.

An implication of the present work is that any methods that aspire to accurately measure response time in-

Table 13

Minimum Cycle Duration and Modal Performances of Each Animation Method as a Function of System Speed, When Animations Were Updated as Quickly as Possible

\begin{tabular}{|c|c|c|c|c|c|c|c|c|c|c|}
\hline \multirow[b]{2}{*}{ Method } & \multicolumn{2}{|c|}{$\begin{array}{c}\text { Cycle } \\
\text { Duration }\end{array}$} & \multicolumn{2}{|c|}{$\begin{array}{l}\text { Standard } \\
\text { Deviation }\end{array}$} & \multicolumn{3}{|c|}{$\begin{array}{l}\text { Slow System Minimum } \\
\text { Modal Performance }\end{array}$} & \multicolumn{3}{|c|}{$\begin{array}{c}\text { Fast System Minimum } \\
\text { Modal Performance }\end{array}$} \\
\hline & Slow & Fast & Slow & Fast & FPI & Duration & $\mathrm{W}: \mathrm{B}$ & FPI & Duration & $\mathrm{W}: \mathrm{B}$ \\
\hline Animated GIF & 478 & 200 & 41 & 30 & 15 & 495 & .35 & 8 & 215 & .63 \\
\hline Javascript/JScript & 240 & 109 & 15 & 8 & 8 & 240 & .44 & 4 & 106 & .50 \\
\hline Java & 116 & 110 & 79 & 30 & 4 & 116 & .58 & 4 & 107 & .50 \\
\hline Flash & 477 & 218 & 79 & 7 & 15 & 500 & .83 & 8 & 214 & .51 \\
\hline Authorware & 1,024 & 85 & 412 & 11 & 31 & 945 & .52 & 3 & 90 & .33 \\
\hline
\end{tabular}

Note-Durations and standard deviations are in milliseconds. FPI is frames per image of the animation, and $\mathrm{W}: \mathrm{B}$ is the ratio of white to black image presentation. 
Table 14

Minimum Cycle Duration and Modal Performances of Each Animation Method as a Function of System Speed, When Animations Were Updated as Quickly as Possible When Animation Images Were 100-msec Durations

\begin{tabular}{|c|c|c|c|c|c|c|c|c|c|c|}
\hline \multirow[b]{2}{*}{ Method } & \multicolumn{2}{|c|}{$\begin{array}{c}\text { Cycle } \\
\text { Duration }\end{array}$} & \multicolumn{2}{|c|}{$\begin{array}{c}\text { Standard } \\
\text { Deviation } \\
\end{array}$} & \multicolumn{3}{|c|}{$\begin{array}{c}\text { Slow System Minimum } \\
\text { Modal Performance }\end{array}$} & \multicolumn{3}{|c|}{$\begin{array}{c}\text { Fast System Minimum } \\
\text { Modal Performance }\end{array}$} \\
\hline & Slow & Fast & Slow & Fast & FPI & Duration & $\mathrm{W}: \mathrm{B}$ & FPI & Duration & $\mathrm{W}: \mathrm{B}$ \\
\hline Animated GIF & 665 & 254 & 154 & 29 & 19 & 667 & .38 & 8 & 280 & .38 \\
\hline Javascript/JScript & 334 & 331 & 58 & 8 & 10 & 333 & .50 & 13 & 333 & .52 \\
\hline Java & 284 & 293 & 15 & 17 & 9 & 285 & .54 & 10 & 285 & .53 \\
\hline Flash & 383 & 233 & 135 & 8 & 20 & 381 & .96 & 8 & 240 & .53 \\
\hline Authorware & 1,107 & 268 & 77 & 19 & 85 & 1,127 & .52 & 9 & 270 & .50 \\
\hline
\end{tabular}

Note-Durations and standard deviations are in milliseconds. FPI is frames per image of the animation, and

$\mathrm{W}: \mathrm{B}$ is the ratio of white to black image presentation.

tervals on the basis of the presentation of some screen image should care about their animation method. The greater the error that is introduced in the stimulus presentation, the greater the error will be in the response time measurement. On laboratory PCs, one has control over many variables, such as the vertical refresh rate of the PC monitor, and experimental design can be modified to ensure that stimulus delivery intervals fall evenly on boundaries that synchronize with the monitor's raster. This step at least reduces the window of variability by the refresh duration. As has been observed in the present work, this is not possible for Web-based experiments, because the refresh rate of the monitor is largely an unknown. Some portion of the subject sample is simply going to be out of phase with the experiment's timing intervals. Hence, on top of error in durations owing to such factors as the operating system, other browser functions, or other programs stealing processing cycles from the animation, there is variability in the mismatch of the experiment durations and the hardware.

\section{Improving Animation Performance}

Several steps can be taken to improve animation performance. First, on the basis of the data presented in the present work, avoid using timing intervals that are below the accuracy boundaries presented in Table 13. This suggests lower bounds on durations of $500 \mathrm{msec}$ for Animated GIF, $240 \mathrm{msec}$ for Javascript/JScript, $120 \mathrm{msec}$ for Java, $500 \mathrm{msec}$ for Flash, and about 1,000 msec for Authorware. Although these data provide an approximation, they remain untested, should be used with caution, and should not be trusted as guaranteeing accuracy. Applying this same logic to some of the data from the present work leads to a false conclusion. For instance, consider the Java animations on MacOS systems in Table 6. All of the timing of a complete cycle is achieved in under $100 \mathrm{msec}$; hence, durations of a single animation image ought to be accurate within this range-after all, a single white image was generally presented in less than $50 \mathrm{msec}$. However, looking at actual performance for a $100-\mathrm{msec}$ timed duration in Table 7 reveals that the interval achieved was generally more than two frames too long. Even the method producing the fastest cycle durations, Authorware on fast Windows systems (whole cy- cles under $50 \mathrm{msec}$; see Table 10), delivered animations with durations timed at $100 \mathrm{msec}$ that were over one frame too long (see Table 11).

A second approach to improving the accuracy of the animation presented is to tailor the animation delivered to the browser that the viewer is using. Browser and OS information are available to experimenters in a number of ways, such as server-side include programs (SSIs; see Schmidt, Hoffman, \& MacDonald, 1997). These programs allow the server to determine what browser the user has and to deliver specialized content on the basis of this information. SSIs could be used to deliver customized animations to the client that have had their durations adjusted to accommodate expected error. Although providing such adjustments is beyond the scope and data of the present paper, one could first determine the animation method to use, estimate the inaccuracies of that method, and then deliver animations that, on the user's system, should achieve the desired duration. For instance, if a client is using Netscape Communicator, the animation method is Javascript/JScript, and the desired image interval is $100 \mathrm{msec}$, then a quick consultation of Table 2 suggests that underspecifying the animation frame by about $50 \mathrm{msec}$ on older Macs and $69 \mathrm{msec}$ on older Windows machines ought to achieve approximately a 100msec duration. The problem with this approach is that the client system speed is not immediately available. Client-side programs (i.e., Authorware, Java, Javascript/ JScript) could further estimate the speed of the computer through timing of empty loops-faster machines would be known to execute long empty loops in less time than do slower machines, and this information could be used to further refine parameter estimates that would achieve the desired interval. Of course, all of these calculations would require an enormous amount of cross-validation to be trustable. Running subjects in the laboratory is probably more desirable than making this effort.

A third approach to improving the accuracy of data collected from Web experiments is to include only data from known browser and operating system configurations in analyses. For instance, if the animation method used is Java and the browser is Netscape Communicator on the Macintosh, then consider excluding the data for accuracy reasons. Data exclusion decisions should, of 
course, be made on an a priori basis in order to avoid introducing Type I errors.

Java was the only animation method examined that proved to be robust with respect to the speed of the observer's system and that produced low variability in its output. This finding highly recommends Java as the method to use. In addition, users of Java have further ways to potentially reduce error in their experiment delivery through additional programming. For example, Eichstaedt (2001) has presented an algorithm in which a parallel thread to the main experiment thread monitors the system clock to determine whether processor cycles have been stolen during the execution of an interval. Trials in which this has occurred during any important presentation intervals can be flagged and either repeated or discarded. The multithreading capabilities of Java make this a solution that other animation methods cannot match. Hecht et al. (1999) have presented additional methods for minimizing stimulus delivery error when using Java, and the reader is referred to these works for ideas.

\section{Conclusions}

The data from the present paper have demonstrated that great variability exists in the timing achieved by a variety of Web animation methods. Caution should be exercised in accepting data acquired by such methods in original research, if acceptable error is outside of the absolute deviations and variation reported in the present work and if fine-timing in the duration of intervals is critical. Although high variability and poor timing control may be sufficient to reproduce known psychological effects given a large enough number of subjects, these uncontrolled variables add further noise (or perhaps systematic variation) than would be encountered in a controlled laboratory environment.

\section{REFERENCES}

Baron, J., \& Siepman, M. (2000). Techniques for creating and using Web questionnaires in research and teaching. In M. H. Birnbaum (Ed.), Psychological experiments on the Internet (pp. 235-265). San Diego: Academic Press.

EICHSTAEDT, J. (2001). An inaccurate-timing filter for reaction time measurement by JAVA applets implementing Internet-based experiments. Behavior Research Methods, Instruments, \& Computers, 33, 179-186.

Finney, S. A. (2001). Real-time data collection in Linux: A case study. Behavior Research Methods, Instruments, \& Computers, 33, 167-173.

Francis, G., Neath, I., \& Surprenant, A. M. (2000). The cognitive psychology online laboratory. In M. H. Birnbaum (Ed.), Psycholog- ical experiments on the Internet (pp. 267-283). San Diego: Academic Press.

Graves., R. E., \& Bradley, R. (1991). Millisecond timing on the IBM $\mathrm{PC} / \mathrm{XT} / \mathrm{AT}$ and PS/2: A review of the options and corrections for the Graves and Bradley algorithm. Behavior Research Methods, Instruments, \& Computers, 23, 377-379.

Hecht, H., Oesker, M., Kaiser, A., Civelek, H., \& Stecker, T. (1999). A perception experiment with time-critical graphics animation on the World-Wide Web. Behavior Research Methods, Instruments, \& Computers, 31, 439-445.

Horswill, M. S., \& Coster, M. E. (2001). User-controlled photographic animations, photograph-based questions, and questionnaires: Three Internet-based instruments for measuring drivers' risk-taking behavior. Behavior Research Methods, Instruments, \& Computers, 33, 46-58.

Inside Web Development (2000). Are you trafficking in illegal GIFs? Inside Web Development, 1, 6-8.

Krantz. J. H. (2000). Tell me, what did you see? The stimulus on computers. Behavior Research Methods, Instruments, \& Computers, 32, 221-229.

Krantz. J. H., Ballard, J., \& Scher, J. (1997). Comparing the results of laboratory and World-Wide Web samples on the determinants of female attractiveness. Behavior Research Methods, Instruments, \& Computers, 29, 264-269.

MACROMEDIA,INC. (2001). Macromedia Flash player adoption statistics [On-line]. Available: http://www.macromedia.com/software/player_ census/flashplayer/ [retrieved February 2, 2001].

McGraw, K. O., Tew, M. D., \& Williams, J. E. (2000a). The integrity of Web-delivered experiments: Can you trust the data? Psychological Science, 11, 502-506.

McGraw, K. O., Tew, M. D., \& Williams, J. E. (2000b). PsychExps: An on-line psychology laboratory. In M. H. Birnbaum (Ed.), Psychological experiments on the Internet (pp. 219-233). San Diego: Academic Press.

McKinney, C. J., MacCormac, E. R., \& Welsh-Bohmer, K. A. (1999). Hardware and software for tachistoscopy: How to make accurate measurements on any PC utilizing the Microsoft Windows operating system. Behavior Research Methods, Instruments, \& Computers, 31, 129-136.

MYoRs, B. (1999). Timing accuracy of PC programs running under DOS and Windows. Behavior Research Methods, Instruments, \& Computers, 31, 322-328.

Schmidt, W. C., Hoffman, R. \& MacDonald, J. (1997). Operate your own World-Wide Web server. Behavior Research Methods, Instruments, \& Computers, 29, 189-193.

Stevenson, A. K., Francis, G., \& Kim, H. (1999). Java experiments for introductory cognitive psychology courses. Behavior Research Methods, Instruments, \& Computers, 31, 99-106.

Welch, N., \& Krantz, J. H. (1996). The World-Wide Web as a medium for psychoacoustical demonstrations and experiments: Experience and results. Behavior Research Methods, Instruments, \& Computers, 28, 192-196.

Williams, J. E., McGraw, K. O., \& Tew, M. D. (1999). Undergraduate labs and computers: The case for PsychExps. Behavioral Research Methods, Instruments, \& Computers, 31, 287-291.

(Manuscript received January 9, 2001; revision accepted for publication January 28, 2001.) 